\title{
Análise das Atribuições Causais do Sucesso e do Insucesso na Competição, em Função do Nível Competitivo dos Futebolistas Portugueses
}

\author{
Analysis of Causal Attributions of Success and Failure in Competitions Regarding \\ Portuguese Soccer Players' Competition Level
}

\author{
Paulo Malico Sousa ${ }^{a}$, António Boleto Rosado ${ }^{* a} \&$ Túlia Maia Cabrita ${ }^{b}$ \\ ${ }^{a}$ Universidade Técnica de Lisboa \& ${ }^{b}$ Universidade Lusiada de Lisboa
}

\begin{abstract}
Resumo
Tendo como referência o modelo atribuicional da motivação e emoção de Weiner (1979), pretendeu-se avaliar as atribuições causais, em situações de sucesso e insucesso desportivo, em função da influência dos diferentes níveis competitivos dos futebolistas portugueses. Analisando uma amostra que integrou 125 futebolistas, que participaram em três níveis competitivos do futebol português (II Divisão; III Divisão; I Divisão Distrital), este estudo apresenta resultados quanto aos mecanismos de perceção de causalidade revelados pelos atletas em função dos diferentes níveis competitivos onde estão inseridos. Os resultados evidenciaram diferenças significativas, nomeadamente no que concerne às dimensões causais referente ao locus de causalidade e controle externo (em situações de sucesso) e locus de causalidade e nível de estabilidade (no caso dos insucessos). Palavras-chave: Atribuições causais; futebol; Modelo atribuicional de Weiner (1979); nível competitivo.
\end{abstract}

\begin{abstract}
Having as a reference Weiner's attributional model of motivation and emotion (1979), this work intended to evaluate the causal attributions, in sport situations of success and failure, in relation to Portuguese soccer players' competitive levels. Studying a sample of 125 soccer players, who compete in three competitive levels (II League; III League; I District League), this study presents results about the mechanisms of causality perception, revealed by the athletes in these 3 different competitive levels. The results had evidenced significant differences between the causal dimensions of locus of causality and external control (success situations) and the locus of causality and level of stability (failure situations).

Keywords: Causal attributions; soccer; Weiner's attributional model; (1979) competitive level.
\end{abstract}

A vida quotidiana é marcada por um esforço de controle dos indivíduos sobre o ambiente que os rodeia. De fato vivemos numa sociedade em que é indispensável compreender o que se passa à nossa volta já que, frequentemente, aquilo que fazemos é objecto de avaliação efetuada por nós próprios e pelos outros.

No âmbito da psicologia social as explicações do senso comum sobre o comportamento dos sujeitos e os acontecimentos complexos da realidade social, constituem o objecto de análise dos modelos de atribuição causal.

Fundamentados na função cognitiva da perceção, estes modelos ocupam-se do conjunto de processos inferenciais e dedutivos através dos quais os indivíduos procuram explicar os comportamentos e acontecimentos que os envolvem, afectam e lhes dizem respeito.

Os processos de imputação de causalidade, isto é, a associação de causas aos acontecimentos, são realizados a todo

* Endereço para correspondência: Departamento de Ciências do Desporto, Faculdade de Motricidade Humana, Universidade Técnica de Lisboa, Cruz Quebrada, Lisboa, Portugal, 1499.E-mail: arosado@fmh.utl.pt o momento quando nos reportamos a contextos de realização (e.g., desportivo, académico, seleção de pessoal).

$\mathrm{Na}$ origem do estudo sobre as atribuições encontram-se os trabalhos de Heider (1944, 1958), unanimemente considerado como o autor pioneiro desta linha de investigação.

Outros lhe sucederam, entre os quais se destacam Jones e Davis (1965) e Kelley (1967, 1972), sendo estes os autores referidos na literatura como os principais nesta área (e.g., Leyens, 1979, 1985; Sousa, 1987, 1996).

Kelley e Michela (1980) consideram que não existe apenas uma teoria da atribuição mas sim várias, classificando-as em atribuitivas e atribuicionais, de acordo com a posição que os processos de inferência ocupam nos modelos de análise da atribuição causal.

Os modelos de Heider (1944, 1958), Jones e Davis (1965) e Kelley $(1967,1972)$ são classificados por Kelley e Michela (1980) como teorias atribuitivas ao passo que o modelo subsequente, apresentado por Weiner $(1972,1979)$, é classificado pelos autores como teoria atribuicional, já que considera, ao contrário dos anteriores, o processo de inferência como uma variável independente, exercendo, por isso, um 
efeito sobre os comportamentos, emoções e expectativas do sujeito (Amâncio, 1998).

No âmbito da teoria de Weiner $(1972,1979)$ a relação entre motivação para a realização e atribuição causal constitui, como referimos anteriormente, uma exceção ao quadro tradicional da atribuição que considera os fatores motivacionais apenas como interferências com efeitos imprevisíveis no processo atribuicional (Sousa, 1996).

O modelo apresentado por Weiner sobre a produção de atribuições causais para explicar os resultados e suas consequências, ao preconizar a utilização predominante de atribuições relacionadas com a capacidade, o esforço, a dificuldade da tarefa e a sorte em contextos de realização, propõe, num primeiro momento, uma taxonomia atribucional envolvendo duas dimensões dicotómicas: a estabilidade com que o efeito varia ao longo do tempo (estável versus instável) e a localização causal ou locus de causalidade (causa interna ao indivíduo ou que se relaciona com o próprio versus fatores externos).

No que respeita ao locus de causalidade, o autor sugere que um bom desempenho atribuído a fatores internos (e.g., a capacidade e o esforço pessoal) gera maior auto-estima do que outro imputado a causas externas. Por sua vez a estabilidade do efeito tem implicações para a expectativa de sucesso ou insucesso futuro. A imputação de causalidade estável tende a gerar expectativas de resultados semelhantes no futuro contrariamente a situações em que a atribuição é associada a fatores instáveis.

A aplicação do modelo bidimensional de Weiner (1972) em contextos diversificados suscitou algumas críticas quanto à sua validade (Brawley \& Roberts, 1984, citado por Biddle, 1993), uma vez que, apesar das duas dimensões iniciais propostas se revelarem úteis, não explicavam, todavia, a totalidade dos resultados. O próprio Weiner (1986) reconheceu esta limitação assinalando que esse modelo era restritivo na explicação das atribuições causais. O autor, admitindo o fato das causas poderem variar de contexto para contexto, tinha já alertado para a possibilidade de existirem outros elementos causais igualmente importantes que deveriam ser considerados pelos investigadores da atribuição.

Assim, Weiner (1979) com o objectivo de aperfeiçoar o seu modelo inicial, incorpora uma terceira dimensão na taxonomia do raciocínio causal: o grau de controlabilidade do efeito. Este fator relaciona-se com a possibilidade da causa ser influenciada pela acção directa do indivíduo ou de terceiros, isto é, passou-se a considerar que uma causa é (in)controlável quando é passível de ser modificada ou afectada por alguém (o próprio ou outro) estando, deste modo, ligada intimamente a aspectos de natureza comportamental.

Em suma, o aspecto nuclear desta teoria centra-se na ideia de que as pessoas organizam o seu pensamento atribuicional em torno das dimensões de Locus de Causalidade, Estabilidade e Controlabilidade.

De salientar, ainda, que posteriormente McAuley, Duncan e Russel (1992) propuseram a divisão da dimensão de controlabilidade em dois fatores distintos, apesar de rela- cionados: o controle pessoal e o controle externo. O controle pessoal refere-se à possibilidade do sujeito dominar a causa em análise, ao passo que o controle externo remete para a possível influência que outras pessoas exercem nessa mesma causa.

Estes autores, com o objectivo de confirmar a sua sugestão, desenvolveram diversos estudos em variados contextos de realização. Os resultados evidenciaram a superioridade do modelo tetrafatorial em relação a outros modelos que integravam um menor número de dimensões, levando assim McAuley et al. (1992) a sugerirem a expansão do modelo tridimensional de Weiner.

Desta forma, a teoria atribuicional da motivação e emoção de Weiner constituiu-se como uma proveitosa estrutura concetual de apoio aos investigadores, já que integra diversos conceitos como a causalidade percebida, as expectativas de (in)sucesso e a diversidade de emoções (Fonseca, 1993b).

Outro dado particularmente importante consiste na assimetria deste modelo para situações de sucesso e insucesso permitindo, assim, a sua aplicação nos mais variados contextos (Sousa, 1996).

De resto, o número de autores que a têm utilizado como suporte teórico dos seus estudos é disso evidência. A teoria de Weiner tem sido aplicada numa considerável diversidade de contextos de realização, desde o académico (e.g., Faria, 1996) passando, por exemplo, pelo clínico (e.g., Fosterling, 1988, citado por Biddle, 1993), pela seleção de pessoal (e.g., Sousa, Cunha \& Ribeiro, 1992) ou, ainda, pelas relações sociais (e.g., Sousa, 1987), até ao âmbito desportivo (e.g., Fonseca, 1993a, 1993b, 1995; Lau \& Russell, 1980; Orbach, Singer \& Murphey, 1997; Si, Rethorst \& Willimczik, 1993).

O modelo de Weiner, de todas as teorias relacionadas com a atribuição, tem sido mesmo o mais utilizado pelos investigadores no que concerne ao contexto desportivo (a este propósito ver: Guallar, Balaguer \& Garcia-Merita, 1993, para uma revisão das bases teóricas utilizadas na investigação das atribuições em contexto desportivo; Biddle, 1993; Biddle \& Hanrahan, 1998; Biddle, Hanrahan \& Sellars, 2001).

Ainda assim, em estudos posteriores, Fonseca (1999) e Fonseca e Brito (2001) salientam que tal constatação não impede que seja recomendada a realização de mais estudos no sentido de tornar o modelo de Weiner mais útil para a compreensão dos comportamentos evidenciados pelos praticantes desportivos. Entre esses estudos, uma variável, a "expertise" ou mestria dos jogadores, deve ser considerada como decisiva para compreender as atribuições causais. $\mathrm{Na}$ realidade, as atribuições de causalidade dos "experts" não têm que ser, necessariamente, idênticas aos dos "nãoexperts" e os trabalhos sobre as atribuições causais em função dos níveis de prática, de mestria desportiva, são uma área importante de estudo no âmbito deste paradigma de investigação.

$\mathrm{Na}$ realidade, em contexto desportivo, poder-se-á afirmar que os níveis competitivos traduzem, em boa medida, diferentes níveis de mestria e de "expertise" dos pratican- 
tes. Segundo Janelle e Hillman (2003) para uma performance de excelência o indivíduo deverá revelar "expertise" em quatro domínios: fisiológico, técnico, emocional e cognitivo. A "expertise" fisiológica envolve o desenvolvimento dos fatores da condição física que determinam o rendimento. Por "expertise" técnica entende-se o grau de coordenação sensorio-motora de onde emergem padrões de movimento refinados, eficientes e eficazes. Na sua aprendizagem deverá ser tida em conta, no treino, não só a execução (eficiência) e o resultado que se pretende obter mediante a sua utilização (eficácia), mas também a sua adaptação às configurações particulares de cada momento do jogo, já que é esta que confere à acção o seu verdadeiro significado. Na realidade, nos Jogos Desportivos Colectivos, à medida que os níveis competitivos se elevam parece que o resultado depende menos de características fisiológicas e técnicas e mais de características cognitivas, estratégias e tácticas, estando o resultado, nos níveis competitivos mais elevados, claramente dependente de aspectos ligados à coordenação interpessoal, ao "entrosamento colectivo", a aspectos de rendimento de expressão colectiva e menos dependentes das performances individuais. A "expertise" em Jogos Desportivos Colectivos é uma "expertise" grupal, que envolve a regulação emocional e faculdades psicológicas da equipa como um todo. A primeira refere-se à capacidade da equipa para monitorar e controlar as emoções. Por seu lado, as faculdades psicológicas, incluem um conjunto de determinantes relacionadas com a performance que podem influenciar o rendimento tal como a motivação, as estratégias de definição de objectivos, a construção da confiança, a manutenção de uma atitude positiva e as faculdades de relacionamento interpessoal (Janelle \& Hillman, 2003). Variações nos níveis competitivos representam diferentes níveis nas capacidades dos jogadores de tomar "decisões no momento" e nas suas faculdades tácticas (Janelle \& Hillman). Na realidade, no âmbito da "expertise" cognitiva, a "expertise" táctica assume-se como um requisito básico para uma performance de excelência.

Nos níveis de performance mais elevados, os jogadores têm de centrar-se em tarefas de acordo com exigências ambientais específicas e com constrangimentos situacionais muito elevados e claramente distintos dos níveis inferiores de prática. As determinações técnicas e fisiológicas mais presentes nos níveis competitivos mais fracos dão lugar a um processamento estratégico aumentado da informação relevante para a realização das tarefas críticas do jogo (Williams \& Ward, 2003). Dodds, Henninger, Patton, Pagnano e Griffin (2003) referem que, conforme os jogadores vão dilatando o conhecimento específico acerca da modalidade praticada, mais facilmente serão capazes de solucionar problemas tácticos.

Uma outra forma de conhecimento - o conhecimento estratégico, (Thomas, 1994), uma forma especial de conhecimento processual que se vai adquirindo no processo de desenvolvimento do jogador e das equipas, vai ser determinante do rendimento nos níveis competitivos mais elevados. Com a elevação do nível de prática as decisões do jogador/equipa são significativamente baseadas no "pla- no estratégico" o qual foi constituído a partir do reportório táctico colectivo. McPherson (1994) refere, ainda, que, para que um "expert" se consolide, em termos da representação de problemas altamente tácticos, assumem-se como requisito necessário extensos anos de prática num elevado nível competitivo. Se é verdade que, no processo de aprendizagem de um determinado desporto, o indivíduo vai acumulando conhecimentos referentes a acções contextualizadas, ficando, cada vez mais, o resultado desportivo dependente de aspectos táctico-estratégicos, de responsabilidade colectiva e menos individual, é de esperar que na avaliação cognitiva das causas dos seus sucessos ou insucessos estes fatores tenham, também, significado, associando os jogadores atribuições de causalidade mais externas, instáveis e passíveis de controle externo aos resultados alcançados (quer aos positivos quer aos negativos).

Assim, perante o exposto anteriormente, os objectivos gerais deste estudo consistem em caracterizar o papel das atribuições causais elaboradas em contexto desportivo, mais especificamente na modalidade de futebol.

Concretamente, nesta investigação procura-se determinar as atribuições efetuadas por futebolistas, para explicarem as causas dos seus resultados em função do nível competitivo em que estão inseridos.

De acordo, portanto, com algumas das indicações anteriores, foi formulada a hipótese de que os futebolistas de diferentes níveis competitivos (II Divisão; III Divisão; I Divisão Distrital) não se assemelham na forma como percecionam as causas subjacentes aos seus resultados mais significativos de sempre (melhor e pior resultado).

\section{Material e Métodos}

\section{Modelo de Estudo}

No que se refere ao objectivo, o estudo é de natureza explicativa, do tipo causal-comparativo, já que se pretende determinar a influência dos diferentes níveis competitivos na atribuição de causalidade efetuada pelos atletas.

Fundamentalmente, pretende-se comparar médias entre grupos pré-definidos, assumindo o trabalho um cariz comparativo, onde se considera que as variáveis independentes são preditoras e, consequentemente, determinantes das dependentes.

\section{Participantes}

A amostra foi constituída por 125 atletas masculinos, de nacionalidade portuguesa, que participaram em vários níveis competitivos (II Divisão, III Divisão e I Divisão Distrital) do escalão sénior do futebol português.

As idades dos inquiridos estão compreendidas entre $18 \mathrm{e}$ 36 anos $(M=25.84 ; D P=3.89)$.

\section{Variáveis em Estudo}

Foram utilizadas como variáveis independentes, ou explicativas, os três níveis competitivos (II Divisão, III Divisão e I Divisão Distrital) onde os futebolistas estavam inseridos. Por outro lado, como variáveis dependentes consideraram-se as dimensões referentes ao locus de causali- 
dade, nível de estabilidade e grau de controlabilidade do modelo atribuicional tridimensional da motivação e emoção de Weiner (1979).

Foram, também, utilizadas variáveis dependentes relativas à avaliação dos jogos (tempo decorrido, nitidez de recordação, perceção de importância e dificuldade do jogo) e à caracterização dos resultados (probabilidade de ocorrência, classificação e satisfação provocada pelo resultado obtido). No entanto, as referidas variáveis são utilizadas no trabalho a título meramente descritivo, permitindo, assim, uma comparação com a tendência de respostas elaboradas pelos atletas nas dimensões causais do modelo de Weiner (1979).

Nessa medida, e embora não constituindo dimensões causais, a recolha de informação acessória decorrente da caracterização destas variáveis proporciona-nos um melhor conhecimento da dinâmica dos resultados, facultando, ao mesmo tempo, a avaliação da sua relevância diferencial no ponto referente à discussão dos mesmos.

\section{Instrumentos}

Foi administrado a todos os futebolistas um questionário constituído por duas secções.

A primeira parte inclui uma secção introdutória destinada à recolha de dados relativos à idade, habilitações literárias, nível competitivo, tempo de prática da modalidade e clube representado pelo atleta.

A segunda parte do questionário, foi preenchida tendo como referência duas realidades diametralmente opostas.
Na primeira fase, os atletas recordaram o jogo em que alcançaram o seu melhor resultado de sempre, respondendo de seguida a diversas questões de forma a caracterizarem não só o jogo e o resultado obtido como também as causas subjacentes a esse mesmo resultado. Numa segunda fase, os indivíduos responderam a um conjunto de perguntas idênticas mas em que a referência passou a ser a competição em que atingiram o seu pior resultado de sempre(ver Figura 1). O critério de escolha do melhor e pior resultado de sempre, bem como a indicação e classificação das causas nas dimensões correspondentes foram da exclusiva responsabilidade dos atletas, não se incorrendo, assim, no que Russell (1982) denominou de "erro fundamental do investigador de atribuição" que consiste no fato de serem os investigadores a caracterizarem dimensionalmente as causas indicadas pelos respondentes.

Deste modo, foram formuladas questões relativas aos jogos (tempo decorrido da sua realização, nitidez de recordação, perceção da sua importância e grau de dificuldade) e aos resultados (probabilidade da sua ocorrência, classificação e satisfação provocada) recordados pelos atletas. Todas estas questões são respondidas em escalas bipolares de Likert de 9 pontos (de $1=$ nenhum ou péssimo a $9=$ muitíssimo ou óptimo). Referindo-se ao melhor e pior resultado de sempre e utilizando a instrução "Gostaríamos que pensasse no jogo em que considera ter alcançado o seu melhor/pior resultado de sempre", os atletas respondiam ao questionário descrito na Figura 1.

A - Há quanto tempo aconteceu?

B - Em que jogo ocorreu?

1. Com que nitidez se lembra desse resultado e das circunstâncias em que aconteceu?

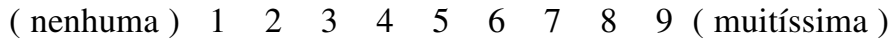

2. Como classifica o resultado que obteve nesse jogo?

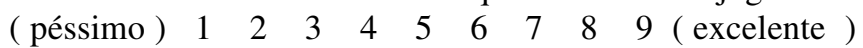

3. Qual era a probabilidade que considerava que esse resultado tinha de acontecer?

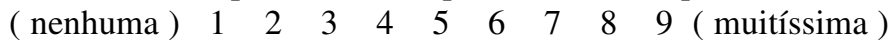

4. Qual a importância que esse jogo tinha para si?

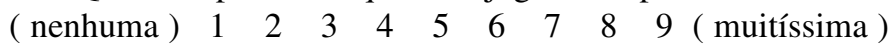

5. Qual era a dificuldade que considerava que tinha esse jogo?

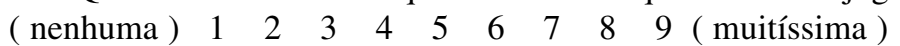

6. Qual foi a sua satisfação por atingir esse resultado?

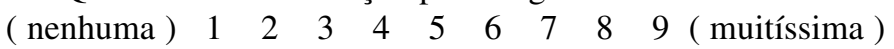

Figura 1. Avaliação do jogo e avaliação do melhor e pior resultado obtido.

$\mathrm{Na}$ avaliação das atribuições causais foi utilizada uma versão traduzida e adaptada para a população portuguesa por Fonseca (1993b) da Causal Dimension Scalle II ([CDSII] McAuley et al., 1992). A CDSII é uma escala que permite aos inquiridos indicarem a causa que consideram ter estado na origem da ocorrência de um determinado resultado, sendo caracterizada ao longo de quatro dimensões: locus de causalidade, estabilidade, controle pessoal e controle externo. A cada dimensão correspondem três itens, respondíveis numa escala bipolar de Likert de 9 


\begin{tabular}{|lllllllllll|}
\hline 1. Que reflecte um aspecto de mim mesmo & 9 & 8 & 7 & 6 & 5 & 4 & 3 & 2 & 1 & Que reflecte um aspecto da situação \\
2. Que pode ser influenciado por mim & 9 & 8 & 7 & 6 & 5 & 4 & 3 & 2 & 1 & Que não pode ser influenciado por mim \\
3. Permanente & 9 & 8 & 7 & 6 & 5 & 4 & 3 & 2 & 1 & Temporário \\
4. Que pode ser regulado por mim & 9 & 8 & 7 & 6 & 5 & 4 & 3 & 2 & 1 & Que não pode ser regulado por mim \\
5. Que as outras pessoas controlam & 9 & 8 & 7 & 6 & 5 & 4 & 3 & 2 & 1 & Que as outras pessoas não controlam \\
6. Que se refere a mim & 9 & 8 & 7 & 6 & 5 & 4 & 3 & 2 & 1 & Que não se refere a mim \\
7. Que é estável no tempo & 9 & 8 & 7 & 6 & 5 & 4 & 3 & 2 & 1 & Que é variável no tempo \\
8. Que está debaixo do poder de outras pessoas & 9 & 8 & 7 & 6 & 5 & 4 & 3 & 2 & 1 & Que não está debaixo do poder de outras pessoas \\
9. Que se relaciona comigo & 9 & 8 & 7 & 6 & 5 & 4 & 3 & 2 & 1 & Que se relaciona com outros \\
10. Que está debaixo do meu poder & 9 & 8 & 7 & 6 & 5 & 4 & 3 & 2 & 1 & Que não está debaixo do meu poder \\
11. Que é inalterável & 9 & 8 & 7 & 6 & 5 & 4 & 3 & 2 & 1 & Que é alterável \\
12. Que as outras pessoas conseguem regular & 9 & 8 & 7 & 6 & 5 & 4 & 3 & 2 & 1 & Que as outras pessoas não conseguem regular \\
\end{tabular}

Figura 2. Avaliação das causas do melhor e do pior resultado.

pontos. A Figura 2 descreve a estrutura essencial da escala utilizada. Referindo-se ao seu melhor e pior resultado de sempre e utilizando a consigne "A causa é (ou as causas são) algo:”, os atletas respondiam ao questionário presente na Figura 2.

Os valores de cada dimensão poderão, portanto, variar entre 3 (mínimo) e 27 (máximo), correspondendo os valores mais elevados a auto-percepções de maior internalidade, estabilidade e passibilidade de controle pessoal e externo das causas consideradas.

Para efeitos deste estudo, foram tidos em conta os resultados de trabalhos anteriores de validação e análise das características psicométricas da adaptação portuguesa da CDSII que confirmam as qualidades desta escala (ver Fonseca \& Maia, 1994, 1995, para uma revisão detalhada da tradução e adaptação deste instrumento).

\section{Procedimentos}

Os questionários foram distribuídos individualmente junto dos atletas antes de uma sessão de treino.
A sua aplicação foi colectiva, nas instalações dos respectivos clubes, sendo a recolha efetuada pelo investigador.

No que concerne à análise e tratamento estatístico, utilizou-se uma estatística paramétrica, tendo sido efetuadas Análises de Variância Multivariada (MANOVA) sobre os "scores" fatoriais de cada uma das dimensões em estudo.

Considerou-se uma probabilidade de erro de $p \leq 0,05$, tendo-se recorrido, para o efeito, ao programa "Statistical Package for Social Sciences - SPSS -Windows".

\section{Apresentação de Resultados}

Para se analisar os resultados em função do nível competitivo foram consideradas três divisões dos campeonatos federados do futebol português - II, III e I Distrital (Associação Futebol Lisboa) - que constituem os três grupos em análise.

As diferenças entre os atletas dos vários níveis competitivos, quando comparadas as suas opiniões em relação à avaliação dos jogos em que obtiveram os seus melhor e pior resultados de sempre, são evidenciadas na Tabela 1.

Tabela 1

Avaliação do Jogo (Tempo Decorrido, Nitidez de Recordação, Importância e Dificuldade) em que Ocorreu o Resultado Recordado. Médias e Desvios-Padrão das Respostas dos Atletas, em Função do Nível Competitivo e do Tipo de Resultado

\begin{tabular}{|c|c|c|c|c|c|c|c|}
\hline \multirow{3}{*}{$\begin{array}{l}\text { Avaliação do Jogo } \\
(N=125)\end{array}$} & \multirow{3}{*}{$\begin{array}{l}\text { Tipo de } \\
\text { Resultado }\end{array}$} & \multicolumn{6}{|c|}{ Nível Competitivo } \\
\hline & & \multicolumn{2}{|c|}{$\begin{array}{c}\mathrm{II} \\
(N=46)\end{array}$} & \multicolumn{2}{|c|}{$\begin{array}{c}\text { III } \\
(N=39)\end{array}$} & \multicolumn{2}{|c|}{$\begin{array}{l}\text { I Distrital } \\
\qquad(N=40)\end{array}$} \\
\hline & & $M$ & $D P$ & $M$ & $D P$ & $M$ & $D P$ \\
\hline \multirow[t]{2}{*}{ Tempo decorrido ${ }^{\mathrm{A}}$} & Sucesso & 4.91 & 3.18 & 4.15 & 3.11 & 6.30 & 4.29 \\
\hline & Insucesso & 5.02 & 3.09 & 4.18 & 3.49 & 5.10 & 3.55 \\
\hline \multirow[t]{2}{*}{ Nitidez de recordação ${ }^{B}$} & Sucesso & 7.85 & 1.15 & 8.08 & .93 & 7.88 & 1.20 \\
\hline & Insucesso & 6.85 & 2.04 & 7.15 & 1.94 & 7.20 & 1.83 \\
\hline \multirow[t]{2}{*}{ Importância do jogo ${ }^{B}$} & Sucesso & 8.39 & .093 & 7.79 & 1.51 & 8.00 & 1.32 \\
\hline & Insucesso & 7.48 & 1.70 & 7.38 & 1.80 & 7.38 & 1.88 \\
\hline \multirow[t]{2}{*}{ Dificuldade do jogo ${ }^{B}$} & Sucesso & 7.43 & 1.39 & 7.51 & 1.32 & 7.50 & 1.96 \\
\hline & Insucesso & 6.59 & 1.98 & 6.38 & 2.11 & 6.05 & 2.04 \\
\hline
\end{tabular}

Notas. $\mathrm{A}=$ valores indicados em anos; $\mathrm{B}=$ valores compreendidos entre 1 e 9 (valores mais elevados indicam maior nitidez, importância e dificuldade do jogo). 
Evidenciaram-se escassas diferenças na forma como os futebolistas caracterizaram o jogo em que obtiveram os seus resultados mais significativos de sempre.

Apenas no tempo decorrido sobre a competição em que obtiveram o seu melhor resultado de sempre se encontraram diferenças estatisticamente significativas $(F(2,122)=3.733$; $p=.027)$, com os atletas da I Distrital a referirem valores significativamente mais elevados que os seus colegas que competiram na III Divisão Nacional (dif. $=2.15 ; p=.022$ ).

Nos restantes parâmetros avaliados (nitidez de recordação, importância e dificuldade do jogo) as diferenças encontradas entre as opiniões dos atletas de cada um dos grupos não se revelaram estatisticamente significativas.

Na Tabela 2 apresentam-se os valores correspondentes ao modo como os jogadores dos diferentes níveis competitivos caracterizaram os resultados obtidos.

Tabela 2

Avaliação do Resultado Obtido (Probabilidade de Ocorrência, Classificação e Satisfação Provocada). Médias e Desvios-Padrão das Respostas dos Futebolistas, em Função do Nível Competitivo e do Tipo de Resultado

\begin{tabular}{|c|c|c|c|c|c|c|c|}
\hline \multirow{3}{*}{$\begin{array}{l}\text { Avaliação do Resultado } \\
(N=125)\end{array}$} & \multirow{3}{*}{$\begin{array}{l}\text { Tipo de } \\
\text { Resultado }\end{array}$} & \multicolumn{6}{|c|}{ Nível Competitivo } \\
\hline & & \multicolumn{2}{|c|}{$\begin{array}{c}\mathrm{II} \\
(N=46)\end{array}$} & \multicolumn{2}{|c|}{$\begin{array}{c}\text { III } \\
(N=39)\end{array}$} & \multicolumn{2}{|c|}{$\begin{array}{l}\text { I Distrital } \\
(N=40)\end{array}$} \\
\hline & & $M$ & $D P$ & $M$ & $D P$ & $M$ & $D P$ \\
\hline \multirow[t]{2}{*}{ Probabilidade de ocorrência ${ }^{A}$} & Sucesso & 5.39 & 2.20 & 5.46 & 1.89 & 5.63 & 1.96 \\
\hline & Insucesso & 4.13 & 2.35 & 4.13 & 1.81 & 4.02 & 2.33 \\
\hline \multirow[t]{2}{*}{ Classificação A } & Sucesso & 8.39 & 1.22 & 8.08 & 1.42 & 8.48 & 1.11 \\
\hline & Insucesso & 2.13 & 1.88 & 1.64 & 1.27 & 2.00 & 1.83 \\
\hline \multirow[t]{2}{*}{ Satisfação provocada ${ }^{\mathrm{A}}$} & Sucesso & 8.87 & .45 & 8.15 & 1.42 & 8.85 & .43 \\
\hline & Insucesso & 1.37 & 1.16 & 1.44 & 1.47 & 1.47 & 1.01 \\
\hline
\end{tabular}

Notas. A= valores compreendidos entre 1 e 9 (valores mais elevados indicam maior probabilidade de ocorrência, classificação e satisfação provocada).

No que respeita à avaliação do resultado obtido os atletas dos diferentes níveis competitivos foram praticamente coincidentes nas respostas dadas. De fato, apenas no parâmetro referente à satisfação provocada pelo melhor resultado se encontram diferenças globais significativas $(F(2,122)=8.756 ; p=.000)$, com os jogadores da II Divisão a evidenciarem uma satisfação significativamente maior que os seus colegas que competiram na III Divisão Nacional $($ dif. $=.72 ; p=.001)$.
Nas restantes dimensões avaliadas, quer no que concerne aos sucessos como aos insucessos, as diferenças não se revelaram suficientes para serem consideradas estatisticamente significativas.

Se nos reportarmos à análise da Tabela 3 verificamos que as diferenças encontradas entre os atletas dos diferentes níveis competitivos foram evidentes, quando considerámos a forma como avaliaram, ao longo das dimensões do modelo de Weiner, as causas por si consideradas como fundamentais para a ocorrência dos seus resultados mais significativos de sempre (melhor e pior resultados).

Tabela 3

Avaliação das Causas (no que Concerne às Dimensões de Locus de Causalidade, Estabilidade e Passibilidade de Controle Pessoal e Externo) Indicadas como Fundamentais para a Obtenção do Resultado Recordado. Médias e Desvios-Padrão das Respostas dos Atletas, em Função do Nível Competitivo e do Tipo de Resultado

\begin{tabular}{|c|c|c|c|c|c|c|c|}
\hline \multirow{3}{*}{$\begin{array}{l}\text { Avaliação das Causas } \\
(N=125)\end{array}$} & \multirow{3}{*}{$\begin{array}{l}\text { Tipo de } \\
\text { Resultado }\end{array}$} & \multicolumn{6}{|c|}{ Nível Competitivo } \\
\hline & & \multicolumn{2}{|c|}{$\begin{array}{c}\mathrm{II} \\
(N=46)\end{array}$} & \multicolumn{2}{|c|}{$\begin{array}{c}\text { III } \\
(N=39)\end{array}$} & \multicolumn{2}{|c|}{$\begin{array}{l}\text { I Distrital } \\
(N=40)\end{array}$} \\
\hline & & $M$ & $D P$ & $M$ & $D P$ & $M$ & $D P$ \\
\hline \multirow[t]{2}{*}{ Locus de causalidade ${ }^{\mathrm{A}}$} & Sucesso & 20.80 & 3.91 & 22.92 & 3.32 & 22.65 & 2.93 \\
\hline & Insucesso & 16.43 & 5.72 & 18.07 & 5.15 & 20.37 & 3.69 \\
\hline \multirow[t]{2}{*}{ Estabilidade ${ }^{\mathrm{A}}$} & Sucesso & 14.80 & 5.60 & 14.05 & 5.09 & 16.50 & 4.27 \\
\hline & Insucesso & 9.06 & 5.82 & 10.61 & 5.32 & 12.20 & 5.91 \\
\hline \multirow[t]{2}{*}{ Controle pessoal ${ }^{\mathrm{A}}$} & Sucesso & 20.45 & 3.98 & 21.94 & 3.67 & 22.25 & 3.74 \\
\hline & Insucesso & 12.84 & 6.65 & 15.92 & 6.88 & 14.10 & 7.09 \\
\hline \multirow[t]{2}{*}{ Controle externo ${ }^{\mathrm{A}}$} & Sucesso & 13.23 & 4.91 & 8.89 & 5.15 & 11.10 & 4.44 \\
\hline & Insucesso & 15.41 & 6.09 & 15.10 & 6.41 & 16.50 & 6.48 \\
\hline
\end{tabular}

Notas. A= valores compreendidos entre 3 e 27 (valores mais elevados indicam auto-perceção de maior internalidade, estabilidade e passibilidade de controle pessoal e externo). 
Com efeito, globalmente salientaram-se diferenças significativas entre os grupos nas dimensões de sucesso referentes ao locus de causalidade $(F(2,122)=4.869 ; p=.009)$ e controle externo $(F(2,122)=8.482 ; p=.000)$ e de insucesso referentes, igualmente, ao locus de causalidade $(F(2,122)=6.730 ; p=.002)$ e ao grau de estabilidade $(F(2,122)=3.237 ; p=.043)$.

Mais especificamente, na dimensão referente ao locus de causalidade em situações de sucesso desportivo, as diferenças significativas encontradas situam-se ao nível dos atletas que competiram na II Divisão em comparação com os dois restantes grupos, isto é, o grupo da II Divisão evidenciou valores significativamente mais baixos que os seus colegas quer da III Divisão (dif. $=-2.1187 ; p=.013$ ), quer, também, da I Distrital (dif. $=-1.8457 ; p=.035$ ).

Situando-nos, ainda, na dimensão referente ao locus de causalidade, mas tendo como referência as situações de insucesso, verifica-se que o grupo da II Divisão classificou as causas dos seus resultados de forma significativamente menos interna que os seus colegas da I Distrital (dif. = 3.9402; $p=.001)$.

Da mesma forma, a dimensão referente à estabilidade nas situações de insucesso foi também classificada de forma significativamente menos elevada em termos estatísticos pelos atletas da II Divisão quando comparados os seus resultados com os dos colegas da I Distrital (dif.= -3.1348; $p=.030)$.

Finalmente, a última diferença estatisticamente significativa encontrada na comparação entre os atletas dos diferentes níveis competitivos, em termos das dimensões atribuicionais do modelo de Weiner, situam-se ao nível do parâmetro referente ao sucesso na dimensão de controle externo.

De fato, os jogadores que competiram a um nível mais elevado (II Divisão) aduziram valores significativamente mais elevados nesta dimensão que os seus colegas que competiram na III Divisão (dif. $=4.3417 ; p=.000$ ).

De referir que nas restantes dimensões as diferenças encontradas não atingiram significado estatístico.

\section{Discussão}

De acordo com a hipótese que havíamos formulado, os dados resultantes deste estudo parecem evidenciar que os atletas de diversos níveis competitivos percecionam de forma diferenciada as causas subjacentes aos seus resultados positivos e negativos.

$\mathrm{Na}$ realidade, verifica-se que os jogadores que competem em divisões superiores desvinculam-se de forma mais pronunciada, tanto dos seus sucessos como dos insucessos, ao considerarem as causas que lhes deram origem como menos internas e menos passíveis de controle pessoal que os seus colegas que competem em níveis inferiores.

Da mesma forma, na avaliação dos piores resultados de sempre, os futebolistas da II Divisão consideram as causas que lhes estiveram subjacentes como mais instáveis em comparação com os demais grupos.
A instabilidade, dimensão comum a todos os grupos nas situações de insucesso, poderá fazer supor uma expectativa de resultado diferente em futuras competições, contribuindo assim, para a manutenção de padrões elevados ao nível da auto-estima.

Quando associada, em resultados negativos, uma dimensão causal instável a um locus de causalidade interno, o que veio a verificar-se em todos os grupos em estudo, os atletas experienciam um sentimento de culpa pelo resultado alcançado motivando, assim, uma orientação no sentido do sucesso em situações competitivas futuras.

Reportando-nos à comparação com estudos anteriores, constatamos que os dados apurados revelam-se, de certa forma, inconsistentes com os resultados de investigações de outros autores ( Fonseca, 1993a; Tenenbaum \& Furst, 1985).

De fato, Tenenbaum e Furst (1985), por exemplo, verificaram que os atletas com uma maior auto-perceção de competência consideravam as causas dos seus resultados como mais internas, estáveis e controláveis do que os seus colegas.

Por outro lado, um estudo de Fonseca (1993a) que envolveu a comparação entre futebolistas profissionais e universitários providenciou suporte, em situações de sucesso, a uma atribuição causal mais interna e passível de controle pessoal por parte dos profissionais quando comparados os seus resultados com os jogadores universitários.

A justificação para os resultados a que chegaram estes autores, completamente antagónicos aos nossos em todas as dimensões do modelo de Weiner, poderá ser encontrada na diferença de terminologia utilizada nestes três estudos. Com efeito, o que Tenenbaum e Furst (1985) denominaram como competência percebida, bem como a comparação entre atletas profissionais e universitários efetuada por Fonseca (1993a), podem não encontrar uma relação directa com os diferentes níveis competitivos em que os atletas estão inseridos no nosso estudo.

Assim, o fato de serem escassas as investigações, tanto em contexto nacional como a nível internacional, que comparem as atribuições causais entre grupos de atletas federados que evoluem em diferentes divisões competitivas, condiciona esta discussão de resultados. Na realidade, a comparação dos dados obtidos neste estudo com os obtidos em estudos anteriores, poderá não estar livre da influência de variáveis contaminadoras. (e.g., terminologia utilizada ou avaliação de constructos diferentes) que desencadeiam os diferentes resultados finais apurados.

Apesar do exposto anteriormente, um dado particularmente interessante deste estudo remete para o fato dos futebolistas, independentemente da divisão em que competem, mencionarem sistematicamente causas mais internas, estáveis e passíveis de controle pessoal na explicação dos seus sucessos quando comparados com os insucessos.

Da mesma forma, os diferentes níveis competitivos não parecem exercer qualquer influência na caracterização do jogo e na avaliação do resultado obtido, já que os atletas inquiridos referiram recordar de forma mais nítida (apesar 
de nalguns casos ter decorrido há mais tempo), deram maior importância e consideraram que envolveu maior grau de dificuldade, embora também com uma maior probabilidade de ocorrência, o jogo em que obtiveram o seu melhor resultado desvalorizando, deste modo, de forma pronunciada, a competição em que não obtiveram sucesso.

Todos estes dados parecem sugerir a existência de uma tendência, mais ou menos clara, para os atletas assumirem, em maior proporção, a responsabilidade do sucesso em detrimento da situação de fracasso. Este fenómeno torna-se mais evidente nos atletas com maior responsabilidade competitiva ao assumirem como menos internas, menos passíveis de controle pessoal e mais instáveis e passíveis de controle externo as causas subjacentes aos resultados negativos.

Nessa medida, será perfeitamente legitimo pensar-se que os atletas que competem em níveis superiores de rendimento utilizam, também, o "self-serving bias" (Biddle, 1993) ou egoísmo atribuicional, como fonte influenciadora da explicação causal dos seus resultados desportivos.

De fato, o egoísmo atribuicional ao referir-se à tendência que as pessoas manifestam, de forma geral, para se responsabilizarem apenas pelos bons resultados que obtêm, utilizando este mecanismo para perceber as causas que levam aos sucessos como mais internas do que as que foram responsáveis por eventuais insucessos, permitiu, provavelmente, aos jogadores efectuarem distorções atribuicionais com o objectivo de protegerem e manterem inalteráveis os seus níveis de auto-estima utilizando, então, este mecanismo como regulador do seu próprio equilíbrio.

Parece, pois, existir uma relação entre os níveis competitivos e o modo como é percebida a causalidade subjacente aos resultados.

Porém, mais estudos serão necessários no sentido de determinar, com maior clareza, os contornos da relação entre atribuições causais e diferentes níveis de competição.

Em última análise, o aumento da eficácia na intervenção psicológica em contexto desportivo, passa, necessariamente, pelo avanço na investigação dos fatores envolvidos no desempenho dos atletas.

\section{Referências}

Amâncio, L. (1998). Masculino e feminino. A construção social da diferença (2. ed.). Lisboa, Portugal: Afrontamento.

Biddle, S. (1993). Attribution research and sport psychology. In R. Singer, M. Murphey \& L. Tennant (Eds.), Handbook of research on sport psychology (pp. 437-463). New York: MacMillan.

Biddle, S., \& Hanrahan, S. (1998). Attributions and attributional style. In J. Duda (Ed.), Advances in sport and exercise psychology measurement (pp. 3-19). Morgantown, KY: FIT.

Biddle, S., Hanrahan, S., \& Sellars, C. (2001). Attributions: Past, present and future. In R. Singer, H. Hausenblas \& C. Janelle (Eds), Handbook of Sport Psychology (2. ed., pp. 444-471). New York: John Wiley \& Sons.

Dodds, P., Henninger, M., Patton, K., Pagnano, K., \& Griffin, L. (2003, March). Exploring novice players' volleyball knowledge in the context situation of game play. Research Quarterly for Exercise and Sport (Suppl.), A-100.
Faria, L. (1996). Desenvolvimento intra individual das atribuições e dimensões causais durante a adolescência. Psicologia (Lisboa), 11(2-3), 121-137.

Fonseca, A. (1993a). Avaliação de atribuições causais no futebol. In S. Serpa, J. Alves, V. Ferreira \& A. P. Brito (Eds), Actas do VIII Congresso Mundial de Psicologia do Desporto (pp. 352-355). Lisboa, Portugal: ISSP.

Fonseca, A. (1993b). Perceção de causalidade subjacente aos resultados desportivos. Dissertação não-publicada, apresentada às provas de aptidão pedagógica e capacidade cientifica, Faculdade de Ciências do Desporto e de Educação Física, Universidade do Porto, Portugal.

Fonseca, A. (1995). A influência do sexo no modo como os atletas percecionam os seus resultados desportivos. Psicologia (Lisboa), 10(1-2), 31-53.

Fonseca, A. (1999). Atribuições em contextos de actividade física ou desportiva: Perspectivas, relações e implicações. Dissertação de Doutorado não-publicada, Universidade do Porto, Portugal.

Fonseca, A., \& Brito, A.P. (2001). A FCDEF-UP e a psicologia do desporto: As atribuições causais. Porto, Portugal: Editora da Universidade do Porto.

Fonseca, A., \& Maia, J. (1994). Avaliação das propriedades psicométricas de um instrumento psicológico, a CDSIIp, a partir da abordagem do LISREL. In L. Almeida \& I. Ribeiro (Eds.), Avaliação psicológica: Formas e contexto: Vol. 2 (pp. 35-42). Braga, Portugal: Associação dos Psicólogos Portugueses.

Fonseca, A., \& Maia, J. (1995). Escala de dimensões causais II (CDSIIp). In L. Almeida, M. Simões \& M. Gonçalves (Eds.), Provas psicológicas em Portugal: Vol. 1 (pp. 103-124). Braga, Portugal: Associação dos Psicólogos Portugueses.

Guallar, A., Balaguer, I., \& Garcia-Merita, M. (1993). A review of the theoretical basis in the study of attribution in sport. In S. Serpa, J. Alves, V. Ferreira \& A .P. Brito (Eds.), Actas do VIII Congresso Mundial de Psicologia do Desporto (pp. 840846). Lisboa, Portugal: ISSP.

Heider, F. (1944). Social perception and phenomenal causality. Psychological Review, 51, 358-374.

Heider, F. (1958). The Psychology of interpersonal relations. New York: Willey.

Jones, E., \& Davis, K. (1965). From acts to dispositions: The attribution process in person perception. In L. Berkowitz (Ed.), Advances in experimental social psychology: Vol. 2 (pp. 219266). New York: Academic Press.

Janelle, C., \& Hillman, C. (2003). Expert performance in sport: Current perspectives and critical issues. In J. Starkes \& K. Ericsson (Eds.), Expert performance in sports. Advances in research on sport expertise (pp. 19-47). Champaign, IL: Human Kinetics.

Kelley, H. (1967). Attribution theory in social psychology. In D. Levine (Ed.), Nebraska Symposium on Motivation: Vol. 15 (pp. 192-238), Lincoln, NE: University of Nebraska.

Kelley, H. (1972). Attribution in social interaction. In E. Jones (Ed.), Attribution: Perceiving the causes of behaviour (pp. 1126). Morristown, NJ: General Learning Press.

Kelley, H., \& Michela, J. (1980). Attribution theory and research. Annual Review of Psychology, 31, 457-501.

Lau, R., \& Russell, D. (1980). Attributions in the sports pages. Journal of Personality and Social Psychology, 39, 29-38.

Leyens, J. P. (1979). Psicologia social. Lisboa, Portugal: Edições 70.

Leyens, J. P. (1985). Teorias da personalidade na dinâmica social. Lisboa, Portugal: Verbo. 
Sousa, P. M., Rosado, A. B. \& Cabrita, T. M. (2008). Análise das Atribuições Causais do Sucesso e do Insucesso na Competição, em Função do Nível Competitivo dos Futebolistas Portugueses.

McAuley, E., Duncan, T., \& Russell, D. (1992). Measuring causal attributions: The revised causal dimenson scale II (CDSII). Personality and Social Psychology Bulletin, 18, 566-573.

McPherson, S. (1994) The development of sport expertise: Mapping the tactical domain. Quest, (46), 223-240.

Orbach, I., Singer, R., \& Murphey, M. (1997). Changing attributions with an attribution training technique related to basketball dribbling. The Sport Psychologist, 11, 294-304.

Russell, D. (1982). The causal dimension scale: A measure of how individuals perceive causes. Journal of Personality and Social Psychology, 42(6), 1137-1145.

Si, G., Rethorst, S., \& Willimczik, K. (1993). Causal attribution perception in sport achievement situation. In S. Serpa, J. Alves, V. Ferreira \& A. P. Brito (Eds.), Actas do VIII Congresso Mundial de Psicologia do Desporto. Lisboa, Portugal: ISSP.

Sousa, E. S. (1987). Attribution in the social context: A conceptual analysis. Unpublished doctoral dissertation, Université Catholique de Louvain, Belgique.

Sousa, E. S. (1996). Atribuição: Da inferência à estratégia de comportamento. In J. Vala \& M. B. Monteiro (Eds.), Psicologia social (2. ed., pp. 141-165). Lisboa, Portugal: Fundação Calouste Gulbenkian.

Sousa, E. S., Cunha, M., \& Ribeiro, R. (1992). Expectativas e padrões de atribuição num processo de seleção. Análise Psicológica, 3(10), 379-389.

Tenenbaum, G., \& Furst, D. (1985). The relationship between sport achievement responsibility, attribution and related situational variables. International Journal of Sport Psychology, 16, 254-269.

Thomas, K. (1994, May). The development of sport expertise: From leeds to MVP legend. Quest, 46(2), 199-210.

Weiner, B. (1972). Theories of motivation. Chicago: Rand Mc Nally.

Weiner, B. (1979). A theory of motivation for some classroom experiences. Journal of Educational Psychology, 71(1), 3-25.

Weiner, B. (1986). An attributional theory of motivation and emotion. New York: Springer Verlag.

Williams, A., \& Ward, P. (2003). Perceptual expertise: Development in sport. In J. Starkes \& K. Ericsson (Eds.), Expert performance in sports. Advances in research on sport expertise (pp. 219-249). Champaign, IL: Human Kinetics. 